Check for updates

Cite this: RSC Adv., 2017, 7, 37654

Received 22nd May 2017 Accepted 15th July 2017

DOI: 10.1039/c7ra05741e

rsc.li/rsc-advances

\section{Enhanced charge collection and stability in planar perovskite solar cells based on a cobalt(III)-complex additive $\uparrow$}

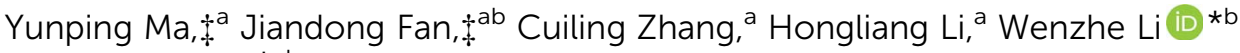 \\ and Yaohua Mai ${ }^{\star a b}$
}

Chemical doping has emerged as a favourable method for tuning the electrical properties of the holetransport layer (HTL) in perovskite solar cells. Herein, we demonstrated an efficient dopant, cobalt(III) complex tris[2-((1H-pyrazol-1-yl)-4-tert-butylpyridine)cobalt(II)tris(bis(trifluoromethylsulfonyl)imide)] (FK209), which exhibited concentration distribution characteristics. The interfacial charge collection is demonstrated to be enhanced. We obtained the optimal power conversion efficiency (PCE) of $17.34 \%$ by optimizing the Co-complex doping ratio. Moreover, we found that the doping of Co-complex into the HTL significantly improved the stability under a sensitive atmosphere.

\section{Introduction}

Perovskite solar cells (PSCs) have been considered to be promising materials due to their ever-increasing power conversion efficiencies, easy manufacture via low temperature processes, and extremely low costs..$^{1-4}$ To achieve high efficiencies, in addition to a high quality perovskite film, an electron-transport layer (ETL) with high electron mobility and a hole-transport layer (HTL) with high hole mobility are required. 2,2',7,7'-Tetrakis ( $N, N$-di-p-methoxyphenylamine) $\quad 9,9^{\prime}$-spirobifluorene (spiroOMeTAD) is commonly used as an efficient hole transport material. ${ }^{5-7}$ Spiro-OMeTAD suffers from both low conductivity and hole mobility in its pristine form, which directly decreases the efficiency. ${ }^{8-11}$

Chemical doping is one of the most useful methods to generate additional charge carriers, which allows for an increase in the charge transport capacity and enhances the conductivity. ${ }^{12}$ The chemical dopant $\mathrm{N}(\mathrm{PhBr})_{3} \mathrm{SbCl}_{6}$ was first introduced to oxidize spiro-OMeTAD, but was rapidly replaced by a more effective additive, lithium bis(trifluoromethanesulfonyl)imide (Li-TFSI). ${ }^{13}$ Li-TFSI can facilitate the oxidation of spiro-OMeTAD by oxygen in air, which thereby allows an increase in the number of charge carriers in spiroOMeTAD. ${ }^{14}$ However, it is difficult to control the amount of the oxidized spiro-OMeTAD and obtain consistent results, which is

\footnotetext{
${ }^{a}$ Institute of Photovoltaics, College of Physics Science and Technology, Hebei University, Baoding, 071002, China.E-mail: yaohuamai@jnu.edu.cn

${ }^{b}$ Institute of New Energy Technology, College of Information Science and Technology, Jinan University, Guangzhou, 510632,China.E-mail: li_wz16@jnu.edu.cn

$\dagger$ Electronic supplementary information (ESI) available: SEM figures of materials and devices, the statistical IV results. See DOI: 10.1039/c7ra05741e

\$ Yunping Ma and Jiandong Fan contributed equal to this work.
}

dependent on various factors including the concentrations of $\mathrm{Li}^{+}$ions and oxygen gas exposure. ${ }^{15}$ To solve this problem, a series of dopants such as cobalt complexes FK209, ${ }^{16}$ and FK102 $;{ }^{17}$ copper salts, CuSCN and CuI; ${ }^{18}$ silver salt Ag-TFSI; ${ }^{19}$ and tin salt $\mathrm{SnCl}_{4}$ were carefully studied. ${ }^{20}$ Among these dopants, Co-complex (FK209) is considered to be a good candidate to improve both the efficiency and reproducibility of the PSCs. ${ }^{21,22}$ Some studies have focussed on Co-complex (FK209) as an oxidant working on spiro-OMeTAD. However, only a few studies have been reported on its concentration distribution in the film and its interfacial function in devices.

In this study, we investigated the concentration distribution and interfacial functions of Co-complex as a dopant in spiroOMeTAD. The study shows the effect of the Co-complex dopant on the charge collection and charge transport properties for the perovskite/HTL interface. The charge collection rate and charge recombination were also investigated via PL and EIS measurement. Based on the dopant, the overall device performance was enhanced, with the PCE as high as $17.34 \%$ and excellent stability under a sensitive atmosphere.

\section{Experimental}

\section{Materials}

$\mathrm{CH}_{3} \mathrm{NH}_{3} \mathrm{I}$ was synthesized by an ice-bath solution-processed approach. Typically, $5 \mathrm{~mL}$ hydroiodic acid ( $57 \mathrm{wt} \%$ in water, Aldrich) was dropwise added to $25 \mathrm{~mL}$ ethanol in a $100 \mathrm{~mL}$ beaker. After stirring the mixed solution for $10 \mathrm{~min}, 6 \mathrm{~mL}$ $\mathrm{CH}_{3} \mathrm{NH}_{2}$ (33\% in ethanol, Aldrich) was added to the obtained solution until the solution turned light yellow. The solution was then stirred for $30 \mathrm{~min}$ at room temperature with an aim of obtaining a uniform precursor. After this, the solution was 
poured into a dish from the beaker and then heated at $100{ }^{\circ} \mathrm{C}$ for $2 \mathrm{~h}$ to obtain white powders.

\section{Solar cell fabrication}

Fluorine tin oxide (FTO)-coated glass with a sheet resistance of $14 \Omega \mathrm{sq}^{-1}$ was washed with deionized water, acetone, ethanol, and isopropanol for $10 \mathrm{~min}$ under sonication and then treated with oxygen plasma for $5 \mathrm{~min}$. A compact layer of $\mathrm{TiO}_{2}$ was deposited on the FTO substrate by spin-coating a titanium precursor (350 $\mu \mathrm{L}$ titanium(Iv) isopropoxide (99.99\%, Aldrich)) in a mixed solvent of $2.5 \mathrm{~mL}$ ethanol and $2 \mathrm{M} \mathrm{HCl}$ in $2.5 \mathrm{~mL}$ ethanol at $2000 \mathrm{rpm}$ for $60 \mathrm{~s}$ followed by calcination in an hot plate at $500{ }^{\circ} \mathrm{C}$ for $30 \mathrm{~min}$. Subsequently, the $\mathrm{TiO}_{2}$-coated FTO substrates were transferred to a nitrogen-filled glovebox and pre-heated at $120^{\circ} \mathrm{C}$ for $15 \mathrm{~min}$.

The synthesized MAI $(0.477 \mathrm{~g})$ was mixed with $\mathrm{PbCl}_{2}(0.278 \mathrm{~g})$ in anhydrous $N, N$-dimethylformamide $(1.392 \mathrm{~mL})$ (DMF, $99.8 \%$, Aldrich) under stirring at room temperature for about $30 \mathrm{~min}$ to produce a clear $\mathrm{CH}_{3} \mathrm{NH}_{3} \mathrm{PbI}_{3-x} \mathrm{Cl}_{x}$ precursor solution with the concentration of $35 \mathrm{wt} \%$. This prepared solution $(100 \mu \mathrm{L})$ was then deposited on the cleaned FTO substrate by spin-coating at $2000 \mathrm{rpm}$ for $45 \mathrm{~s}$. The obtained $\mathrm{CH}_{3} \mathrm{NH}_{3} \mathrm{PbI}_{3-x} \mathrm{Cl}_{x}$ film was then annealed at $90{ }^{\circ} \mathrm{C}$ for $160 \mathrm{~min}$ and then heated to $120{ }^{\circ} \mathrm{C}$ for $17 \mathrm{~min}$ in a glove box.

The HTL solution was prepared by dissolving $300 \mathrm{mg}$ spiroOMeTAD (99.5\%, Xi'an polymer Light Technology Corp) in 2.91 $\mathrm{mL}$ chlorobenzene $(99.8 \%$, Aldrich) and then adding the Cocomplex (99\%, Dyenamo) stock solution $\left(180 \mathrm{mg} \mathrm{mL} \mathrm{m}^{-1}\right.$ in acetonitrile). In addition, $29 \mu \mathrm{L}$ tBP $(96 \%$, Aldrich) and $126 \mu \mathrm{L}$ Li-TSFI $\left(98 \%\right.$, Aldrich) stock solution $\left(170 \mathrm{mg} \mathrm{mL}^{-1}\right.$ in acetonitrile) were added as additives. For comparison, the same concentrations of spiro-OMeTAD solution-doped Li-TSFI and tBP were also prepared. The HTM solution was prepared by spin-coating at $3000 \mathrm{rpm}$ for $45 \mathrm{~s}$, and then, the cell was completed by thermally evaporating a $120 \mathrm{~nm}$ thick silver layer.

\section{Characterizations}

Time-of-flight secondary ion mass spectrometry (ToF-SIMS) measurement was used to profile organic materials for elemental analysis with Ar cluster ions or C60 ions. Impedance spectroscopy measurement was performed using an impedance analyzer (Zahner PP211). Different bias potentials ranging from $0.5 \mathrm{~V}$ to $0.9 \mathrm{~V}$ were applied to each cell under dark conditions. A voltage perturbation with $10 \mathrm{mV}$ of amplitude was applied at the frequencies between $100 \mathrm{kHz}$ and $0.1 \mathrm{~Hz}$. The measurement results were fitted with the software Z-View. Conductivity measurement of the FTO/HTL/Ag hole only devices was conducted under ambient conditions using a sourcemeter (Agilent B1500A) in a two-point contact setup. Moreover, $400 \mathrm{~nm}$ thick different HTLs were deposited by spin-coating on a glass substrate, and then, a $100 \mathrm{~nm}$-thick silver layer was deposited by thermal evaporation through a shadow mask (channel length: 2 $\mathrm{mm}$; channel width: $20 \mathrm{~mm}$ ). Current-voltage $(J-V)$ characteristics of the perovskite solar cells were measured using a semiconductor device analyzer (Keithley 2601B) and a SAN-EI solar simulator (XES-100S1) with an AM 1.5 G spectrum. The light intensity on the sample was adjusted to $1000 \mathrm{~W} \mathrm{~m}^{-2}$ using a standard Si cell (RS-ID-4). The scan rate was fixed to $0.15 \mathrm{~V} \mathrm{~s}^{-1}$. A black mask with an aperture $\left(9 \mathrm{~mm}^{2}\right)$ was placed on the top of the device to control the effective electrode area. PL spectra were obtained by time correlated single photon counting using FLS 920 (Edinburgh Instruments). The experiment was performed with an excitation laser wavelength of $470 \mathrm{~nm}$ and monitored at $780 \mathrm{~nm}$ emission. Field-emission scanning electron microscopy (SEM) was used to characterize the morphology of the obtained thin film. Both top-down and cross-sectional views were obtained using FEI NovaNanoSEM450. The crystal structure was characterized by a Bruker D8 Advance X-ray diffractometer (XRD) with $\mathrm{Cu} \mathrm{K} \alpha$ radiation at $40 \mathrm{kV}$ and $40 \mathrm{~mA}$.

\section{Results and discussion}

We fabricated the Co-complex and Li-TFSI doped spiroOMeTAD layer on the perovskite film. The thickness of the spiro-OMeTAD layer is about $400 \mathrm{~nm}$, which is shown in Fig. S1. $\dagger$ The target film was measured by time-of-flight secondary ion mass spectrometry (ToF-SIMS) (Fig. 1). The positions of different layers through the depth profile of the entire device were estimated via detection of the dominant secondary-ion signal for various layers. Note that the concentration of $\mathrm{Co}^{+}$is higher at 2000-3000 s, and $\mathrm{Pb}^{-}$is growing during the same time period. Because the Co dopant concentration is just $4 \mathrm{~mol} \%$ in spiro-OMeTAD, the amplitude of the Co-curve is much smaller than that of the $\mathrm{Pb}$-curve. The results indicate that the Co-complex is enriched at the interface between the perovskite and HTL. To further identify this result, we also conducted energy dispersive spectrometer (EDS) measurement, as shown in Fig. 1b. The result is consistent with the ToF-SIMS result.

The dopant concentrated at the interface is supposed to influence the charge collection properties. Thus, we have investigated the transfer kinetic process of charge carriers from perovskite to HTL with and without the Co-complex dopant, which have been marked as FLS and LS, respectively. The photoluminescence (PL) measurement was carried out on the glass/perovskite/HTL films. Fig. 2a shows the steady-state PL spectra. We found that the characteristic emission peak of $\mathrm{CH}_{3} \mathrm{NH}_{3} \mathrm{PbI}_{3-x} \mathrm{Cl}_{x}$ was at $\sim 774 \mathrm{~nm}$, which was in accordance with previous reports. ${ }^{23,24}$ In the case of the FLS sample, the PL
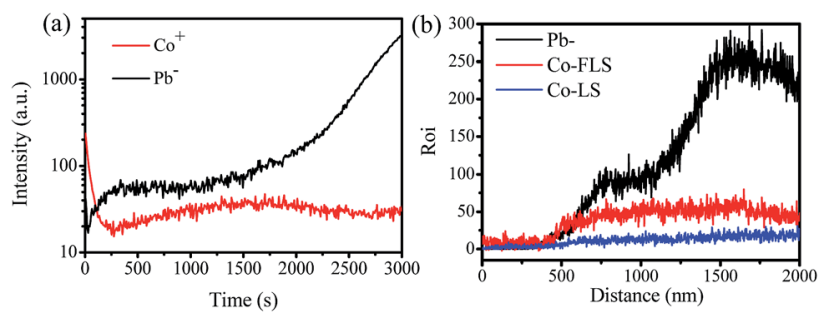

Fig. 1 (a) Time-of-flight secondary ion mass spectrometry of the HTL deposited on $\mathrm{FTO} / \mathrm{c}-\mathrm{TiO}_{2} / \mathrm{MAPbl}_{3-x} \mathrm{Cl}_{x}$ with a Co-complex dopant and (b) energy dispersive spectrometer linear scan of the cross-section element of the device with and without doped Co-complex in the HTL. 

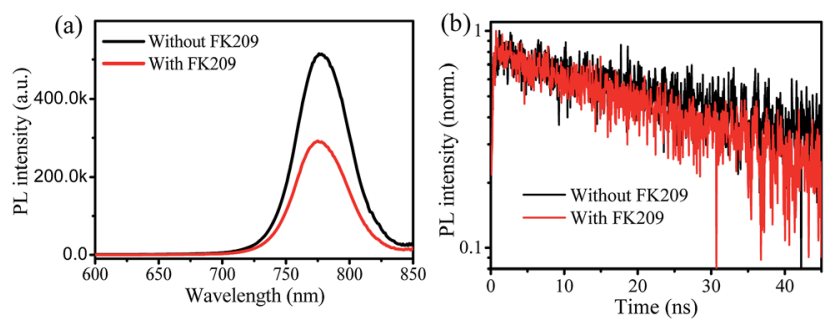

Fig. 2 (a) Steady-state photoluminescence spectra of the perovskite thin films with the HTL doped with and without Co-complex dopant and (b) the time-resolved photoluminescence spectra of the HTL.

intensity is quenched by nearly $40 \%$, thus demonstrating a more effective charge transport in comparison with that in the FK209 doped HTL. ${ }^{25}$ Further, time-resolved PL decay curves are shown in Fig. 2b. The faster quenching and shorter lifetime of the excited state are shown and they indicate the shortened rate for charge transfer at the interface between the perovskite and FLS HTL.

We fabricated the full solar cell devices. The cross-sectional image of the typical devices with a structure of FTO/compacted- $\mathrm{TiO}_{2} / \mathrm{CH}_{3} \mathrm{NH}_{3} \mathrm{PbI}_{3-x} \mathrm{Cl}_{x} / \mathrm{HTL} / \mathrm{Ag}$ is shown in Fig. S1. $\dagger$ The top-down view and XRD patterns of the perovskite film are shown in Fig. S2, $\uparrow$ which indicate that the obtained film is homogeneous and has high coverage. ${ }^{26,27}$ Based on the wellfabricated devices, we investigated the interface performance including the charge transport, recombination, and accumulation for perovskite solar cells by electrical impedance spectroscopy (EIS) measurement. ${ }^{28-31}$ The Nyquist plots of the devices in Fig. 3a were acquired in the frequency range from $1 \mathrm{~Hz}$ to $100 \mathrm{kHz}$ in weak light and under different biases. We have used a two-lumped $R C$ circuit in a series to fit the impedance data, which was generally used in the literature. ${ }^{32,33}$ The arcs in the high frequency region are mainly attributed to the charge contact resistance through the interface of the c- $\mathrm{TiO}_{2} / \mathrm{CH}_{3} \mathrm{NH}_{3} \mathrm{PbI}_{3-x} \mathrm{Cl}_{x} /$ spiro-OMeTAD contact, ${ }^{31,33}$ with two typical impedance elements of charge contact resistance $\left(R_{\text {con }}\right)$ and geometrical capacitance $(C)$. The arc in the middle frequency region corresponds to the charge recombination process at the compact-TiO ${ }_{2} /$ perovskite or perovskite/HTL interface, where the interfacial recombination resistance $\left(R_{\text {rec }}\right)$ and chemical capacitance $\left(C_{\mu}\right)$ can be extracted. In addition, the
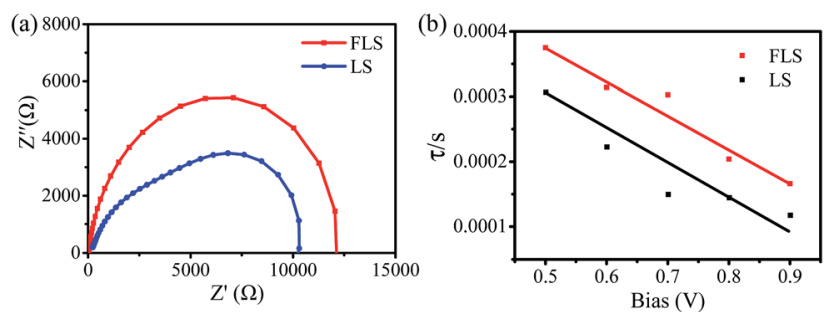

Fig. 3 (a) Nyquist plots of the devices with and without the Cocomplex dopant hole transport layer measured under dark conditions and (b) the charge recombination lifetime for devices under different bias voltages. charge recombination lifetime $\tau\left(\tau=R_{\text {rec }} C_{\mu}\right)$ in the middle frequency region was determined, as shown in Fig. 3b. The device with a Co-complex-dopant exhibited a longer recombination lifetime than the device without the Co-complex-dopant. Thus, the Co-complex doped into HTL significantly improves the charge transport and reduces the charge recombination.

The enhancement of the interfacial properties is supposed to be attributed to the presence of the Co-complex at the interface. Then, we measured the conductivity of the HTL films with different Co-complex concentrations. The conductivities are carefully compared in Fig. $4 \mathrm{a}$ and $\mathrm{b}$. The conductivity of pristine spiro-OMeTAD is $3.8 \times 10^{-8} \mathrm{~S} \mathrm{~cm}^{-1}$, which is similar to the previous report. ${ }^{34}$ Surprisingly, with the increasing doping concentration, the curve shows a maximum conductivity of $4.6 \times 10^{-5} \mathrm{~S} \mathrm{~cm}^{-1}$, which increases by three orders of magnitude than that of the film without a Co-complex dopant. This result indicates that the doping of the Co-complex into spiroOMeTAD improves the intrinsic conductivity as the concentration increases to $8 \mathrm{~mol} \%$. The dramatic enhancement of the conductivity with the Co-complex dopant is associated with the presence of more holes during the oxidization process of spiroOMeTAD.

We further optimized the power conversion efficiency (PCE) of the PSC devices via controlling the concentration of the Cocomplex dopant. The parametric statistical results are shown in Fig. S3a. $\uparrow$ The results show that the optimized concentration is $4 \mathrm{~mol} \%$. Interestingly, the variation trend of PCE is different from the conductivity evolution with the dopant concentration, which would be associated to the concentration increase at the interface. As shown in Table 1 , the open circuit voltage $\left(V_{\text {OC }}\right)$ and short circuit current density $\left(J_{\mathrm{SC}}\right)$ were clearly improved when the Co-complex was doped, leading to a substantial improvement in the average PCE from $13.8 \%$ to $16.8 \%$. The statistical data of PCEs are obtained from 30 devices of different batches. Fig. 5 shows the $J-V$ curves of the champion cell. The device without the Co-complex dopant showed a comparably low efficiency of $14.59 \%$ with a $J_{\text {SC }}$ of $21.12 \mathrm{~mA} \mathrm{~cm}^{-2}$, an $V_{\text {OC }}$ of $0.93 \mathrm{~V}$, and a FF of 0.74 . Impressively, when the doped concentration of the Co-complex dopant was $4 \mathrm{~mol} \%$, the efficiency reached $17.34 \%$ with a $J_{\mathrm{SC}}$ of $22 \mathrm{~mA} \mathrm{~cm}^{-2}$, a $V_{\text {OC }}$ of $1.02 \mathrm{~V}$, and a FF of 0.77 . Although hysteresis still exists, there is an obvious reduction with the Co-complex dopant from 0.37 to 0.26. This may be due to the faster charge transport and fewer defects after Co-complex modified the interface between (a)

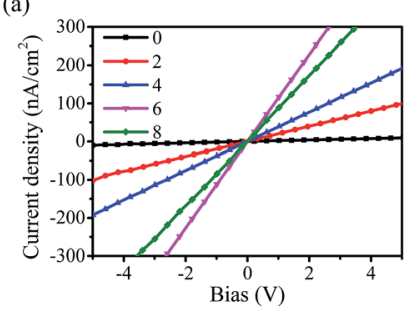

(b)

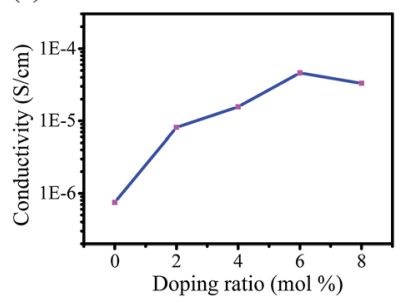

Fig. 4 (a) Linear $I-V$ curves for different doping concentrations of the Co-complex and (b) the corresponding conductivity for different doping concentrations of the Co-complex. 
Table 1 Photovoltaic parameters of the studied PH PVKSCs with and without the Co-complex dopant

\begin{tabular}{lllrr}
\hline Device & Scanning direction & $V_{\mathrm{OC}}(\mathrm{V})$ & $J_{\mathrm{SC}}\left(\mathrm{mA} \mathrm{cm}^{-2}\right)$ & FF $(\%)$ \\
\hline LS & Forward & $0.75 \pm 0.05$ & $21.0 \pm 0.5$ & $0.51 \pm 0.06$ \\
& Reverse & $0.91 \pm 0.03$ & $20.9 \pm 0.4$ & $0.72 \pm 0.04$ \\
FLS & Forward & $0.85 \pm 0.05$ & $21.6 \pm 0.5$ & $0.63 \pm 0.04$ \\
& Reverse & $1.01 \pm 0.03$ & $21.8 \pm 0.4$ & $0.7 \pm \pm 0.02$
\end{tabular}

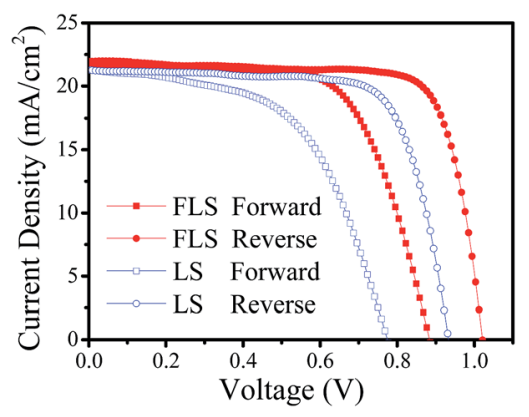

Fig. $5 \mathrm{~J}-V$ curves obtained under optimized conditions with and without the Co-complex dopant measured under simulated AM 1.5 sunlight of $100 \mathrm{~mW} \mathrm{~cm}^{-2}$ irradiance.

perovskite and spiro-OMeTAD. ${ }^{35}$ We observed that the rather higher conversion efficiency of the device with the Co-complex dopant can be ascribed to its higher $V_{\mathrm{OC}}, J_{\mathrm{SC}}$, and FF. These results can be attributed to the lower Fermi level with the Cocomplex dopant, ${ }^{36}$ as shown in Fig. $\mathrm{S} 4, \dagger$ higher conductivity of the HTL at the interface, and faster charge collection. The $J_{\mathrm{SC}}$ data acquired from the $J-V$ curve is consistent with the integrated current density of $22 \mathrm{~mA} \mathrm{~cm}{ }^{-2}$ obtained from the monochromatic incident photon-to-electron conversion efficiency (IPCE) shown in Fig. S3b. $\dagger$

Finally, we investigated the device stability. Fig. 6a shows the light stability under 1 sun AM1.5G illumination in the packing bag at a temperature of $40{ }^{\circ} \mathrm{C}$ for 9 hours. The device without the Co-complex dopant shows a poor stability upon light soaking, which retains only about $30 \%$ of the initial performance within 9 hours. Conversely, the device with the Co-complex-dopant was much more stable, with a good retention of $80 \%$. Fig. $6 \mathrm{~b}$ shows the thermal stability under a nitrogen atmosphere at $60{ }^{\circ} \mathrm{C}$ and humidity less than $20 \%$. Similarly, the PCE decreased to nearly
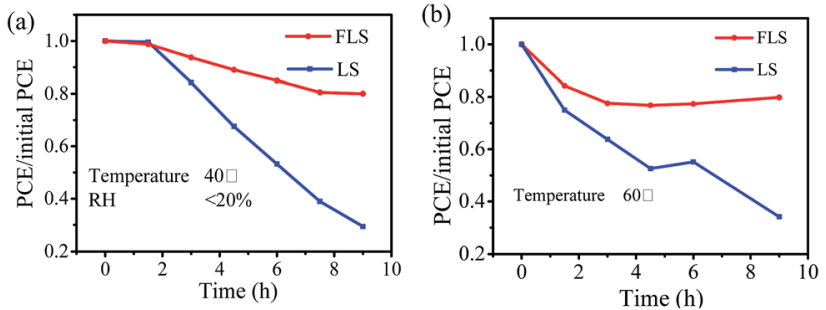

Fig. 6 Normalized PCE evolution of devices with 9 hours under the conditions of (a) light soaking in the packing bag at a temperature of $40{ }^{\circ} \mathrm{C}$ and 1 sun AM1.5G illumination and (b) thermal treatment at $60{ }^{\circ} \mathrm{C}$ under a $\mathrm{N}_{2}$ environment.
$30 \%$ in 9 hours. With the Co-complex dopant, the PCE was maintained above $80 \%$. We also measured the stability under a humid air atmosphere, as shown in Fig. $55, \dagger$ and a comparatively good stability was observed. The Co-complex on the perovskite and HTL interface suppresses traps, such that there is less degradation of the device with the Co-complex dopant, which may contribute to the enhancement of interfacial polarity compatibility.

\section{Conclusions}

In this study, we employed a Co-complex as a dopant in the spiro-OMeTAD hole transport material. The dopant concentration was shown to be higher in the HTL and perovskite interface, which could thereby enhance the charge carrier collection and transfer. With the extraordinary merits of the modified HTL, we have effectively improved the solar cell efficiency as high as $17.34 \%$, and remarkable device stability has been achieved. Moreover, using of effective chemical doping to tune the charge collection and transport properties is a straightforward method for organic semiconductors, which can be a promising route to fabricate highly efficient and stable PSCs.

\section{Acknowledgements}

The research was funded by the National Natural Science Foundation of China (No. 51672111), Advanced Talents Program of Hebei Province (No. GCC2014013), Top Young Outstanding Innovative Talents Program of Hebei Province (No. BJ2014009), Natural Science Foundation of Hebei Province (No. F2015201189), and J. Fan thanks for the support of "100 Talents Program of Hebei Province” (E2014100008).

\section{References}

1 M. M. Lee, J. Teuscher, T. Miyasaka, T. N. Murakami and H. J. Snaith, Science, 2012, 338, 643-647.

2 H. S. Jung and N. Park, Small, 2015, 11, 10-25.

3 G. E. Eperon, V. M. Burlakov, P. Docampo, A. Goriely and H. J. Snaith, Adv. Funct. Mater., 2014, 24, 151-157.

4 G. C. Xing, N. Mathews, S. Y. Sun, S. S. Lim, Y. M. Lam, M. Gratzel, S. Mhaisalkar and T. C. Sum, Science, 2013, 342, 344-347.

5 S. Kazim, M. K. Nazeeruddin, M. Gratzel and S. Ahmad, Angew. Chem., Int. Ed., 2014, 53, 2812-2824.

6 J. Salbeck, F. Weissörtel and J. Bauer, Macromol. Symp., 1998, 125, 121-132. 
7 I. Chung, B. Lee, J. He, R. P. H. Chang and M. G. Kanatzidis, Nature, 2012, 485, 486-489.

8 L. Yang, B. Xu, D. Q. Bi, H. N. Tian, G. Boschloo, L. C. Sun, A. Hagfeldt and E. M. J. Johansson, J. Am. Chem. Soc., 2013, 135, 7378-7385.

9 T. Leijtens, I. K. Ding, T. Giovenzana, J. T. Bloking, M. D. McGehee and A. Sellinger, ACS Nano, 2012, 6, 14551462.

10 F. Fabregat-Santiago, J. Bisquert, E. Palomares, S. A. Haque and J. R. Durrant, J. Appl. Phys., 2006, 100, 034510.

11 R. Schölin, M. H. Karlsson, S. K. Eriksson, H. Siegbahn, E. M. J. Johansson and H. Rensmo, J. Phys. Chem. C, 2012, 116, 26300-26305.

12 H. Xi, X. H. Ma, J. J. Chang, D. Z. Chen, Z. H. Lin, P. Zhong, H. Wang and C. F. Zhang, ACS Omega, 2017, 2, 326-336.

13 U. Bach, D. Lupo, P. Comte, J. Moser, F. Weissörtel, J. Salbeck, H. Spreitzer and M. Gratzel, Nature, 1998, 395, 583-585.

14 S. Wang, W. Yuan and Y. S. Meng, ACS Appl. Mater. Interfaces, 2015, 7, 24791-24798.

15 A. Abate, T. Leijtens, S. Pathak, J. Teuscher, R. Avolio, M. E. Errico, J. Kirkpatrik, J. M. Ball, P. Docampo, I. McPherson and H. J. Snaith, Phys. Chem. Chem. Phys., 2013, 15, 2572-2579.

16 J. Burschka, F. Kessler, M. K. Nazeeruddin and M. Graetzel, Chem. Mater., 2013, 25, 2986-2990.

17 J. Burschka, A. Dualeh, F. Kessler, E. Baranoff, N.-L. CeveyHa, C. Yi, M. K. Nazeeruddin and M. Gratzel, J. Am. Chem. Soc., 2011, 133, 18042-18045.

18 M. Li, Z. K. Wang, Y. G. Yang, Y. Hu, S. L. Feng, J. M. Wang, X. Y. Gao and L. S. Liao, Adv. Energy Mater., 2016, 6, 1601156.

19 P. Wang, J. Zhang, Z. B. Zeng, R. J. Chen, X. K. Huang, L. M. Wang, J. Xu, Z. Y. Hu and Y. J. Zhu, J. Mater. Chem. C, 2016, 4, 9003-9008.

20 M. Xu, Y. Rong, Z. Ku, A. Mei, X. Li and H. Han, J. Phys. Chem. C, 2013, 117, 22492-22496.

21 D. Q. Bi, W. G. Tress, M. I. Dar, P. Gao, J. S. Luo, C. Renevier, K. Schenk, A. Abate, F. Giordano, J. C. Baena, J. Decoppet, S. M. Zakeeruddin, M. K. Nazeeruddin, M. Gratzel and A. Hagfeldt, Sci. Adv., 2016, 2, 1501170.
22 K. T. Cho, S. Paek, G. Grancini, C. Roldán-Carmona, P. Gao, Y. Lee and M. K. Nazeeruddin, Energy Environ. Sci., 2017, 10, 621-627.

23 W. Z. Li, W. Zhang, S. V. Reenen, R. J. Sutton, J. D. Fan, A. A. Haghighirad, M. B. Johnston, L. D. Wang and H. J. Snaith, Energy Environ. Sci., 2016, 9, 490-498.

24 N. K. Noel, A. Abate, S. D. Stranks, E. Parrott, V. Burlakov, A. Goriely and H. J. Snaith, ACS Nano, 2014, 8, 9815-9821.

25 Y. Wang, R. Fullon, M. Acerce, C. E. Petoukhoff, J. Yang, C. G. Chen, S. N. Du, S. K. Lai, S. P. Lau, D. Voiry, D. O'Carroll, G. Gupta, A. D. Mohite, S. D. Zhang, H. Zhou and M. Chhowalla, Adv. Mater., 2017, 29, 1603995.

26 W. Z. Li, J. D. Fan, Y. H. Mai and L. D. Wang, Adv. Energy Mater., 2016, 1601433.

27 Y. L. Li, W. H. Sun, W. B. Yan, S. Y. Ye, H. T. Peng, Z. W. Liu, Z. Q. Bian and C. H. Huang, Adv. Funct. Mater., 2015, 25, 4867-4873.

28 H. S. Kim, I. Mora-Sero, V. Gonzalez-Pedro, F. FabregatSantiago, E. J. Juarez-Perez, N. G. Park and J. Bisquert, Nat. Commun., 2013, 4, 2242.

29 A. Dualeh, T. Moehl, N. Tetreault, J. Teuscher, P. Gao, M. K. Nazeeruddin and M. Gratzel, ACS Nano, 2014, 8, 362-373.

30 V. Gonzalez-Pedro, E. J. Juarez-Perez, W. S. Arsyad, E. M. Barea, F. Fabregat-Santiago, I. Mora-Sero and J. Bisquert, Nano Lett., 2014, 14, 888-893.

31 E. J. Juarez-Perez, M. Wußler, F. Fabregat-Santiago, K. LakusWollny, E. Mankel, T. Mayer, W. Jaegermann and I. Mora-Sero, J. Phys. Chem. Lett., 2014, 5, 680-685.

32 A. Pockett, G. E. Eperon, T. Peltola, H. J. Snaith, A. Walker, L. M. Peter and P. J. Cameron, J. Phys. Chem. C, 2015, 119, 3456-3465.

33 W. W. Wang, J. Y. Yuan, G. Z. Shi, X. X. Zhu, S. H. Shi, Z. K. Liu, L. Han, H. Q. Wang and W. L. Ma, ACS Appl. Mater. Interfaces, 2015, 7, 3994-3999.

34 B. Xu, J. Huang, H. Agren, L. Kloo, A. Hagfeldt and L. C. Sun, ChemSusChem, 2014, 7, 3252-3256.

35 J. H. Heo, D. H. Song, H. J. Han, S. Y. Kim, J. H. Kim, D. Kim, H. W. Shin, T. K. Ahn, C. Wolf, T. W. Lee and S. H. Im, Adv. Mater., 2015, 27, 3424-3430.

36 J. Noh, N. J. Jeon, Y. C. Choi, M. K. Nazeeruddin, M. Gratzel and S. I. Seok, J. Mater. Chem. A, 2013, 1, 11842-11847. 